\title{
Music performance anxiety and its relationship with social phobia and dimensions of perfectionism
}

Research Studies in Music Education

@SAGE

\section{Bianka Dobos}

University of Szeged, Hungary

\section{Bettina F. Piko}

University of Szeged, Hungary

\section{Dianna T. Kenny}

The University of Sydney, Australia

\begin{abstract}
Although music performance anxiety (MPA) is a common problem, there are only a few studies on this subject in Hungary. In this article, we investigate the underlying socio-demographic and psychological factors related to music performance anxiety. The sample consisted of musicians ( $N=100$; aged between 15-35 years) who were studying or had completed their musical education. Study participants completed the Kenny Music Performance Anxiety Inventory, Frost Multidimensional Perfectionism Scale, Social Phobia Inventory and other music-related questions. Females reported higher levels of MPA and social anxiety without a significant difference in perfectionism. Social phobia and perfectionism were significantly correlated with MPA. In multiple regression analysis four out of six subscales of perfectionism significantly predicted MPA, among which Parental Criticism and Doubts about Actions were positive, while Parental Expectations and Preference for Organization were negative predictors. We conclude that there is a strong interrelationship among MPA, social anxiety, and perfectionism. Findings suggest that in some cases of MPA there may also be co-morbid, non-performance related social phobia. These results indicate that MPA is complex and multi-factorial, with possible early onset, thus alerting parents, teachers, and mental health professionals to the value of early recognition, management, and intervention.
\end{abstract}

\section{Keywords}

fear of negative evaluation, musicians, music performance anxiety (MPA), perfectionism, social phobia

\section{Corresponding author:}

Bettina F. Piko, Department of Behavioral Sciences, University of Szeged, Szentharomsag str. 5., Szeged, 6722 , Hungary.

Email: fuze.piko.bettina@med.u-szeged.hu 


\section{Introduction}

Performance anxiety is frequently experienced by people taking a test (Park, Ramirez, \& Beilock, 2014), giving a speech (Goberman, Hughes, \& Haydock, 2011), or performing music (Kenny \& Ackermann, 2015; Kenny \& Osborne, 2006; Walker \& Nordin-Bates, 2010). Performance anxiety occurs in performance situations of high threat in which fear of negative evaluation is prominent. Many musicians admit "experiencing stress related to performance" (Bartel \& Thompson, 1994, p. 72) or being anxious or nervous in front of an audience. It is estimated that between $15 \%$ and $50 \%$ of musicians suffer from music performance anxiety (MPA) severe enough to interfere with the quality of their performances (Kenny, 2011).

Since MPA is a serious problem for many musicians, it has been widely studied among different age groups and genres of music. Previous studies have involved children (Boucher \& Ryan, 2011), adolescents (Nusseck, Zander, \& Spahn, 2015; Osborne \& Kenny, 2005, 2008), and adult musicians (Ackermann, Kenny, O’Brien, \& Driscoll, 2014; Kenny, Davis, \& Oates, 2004; Kenny, Driscoll, \& Ackermann, 2014, 2016; Larrouy-Maestri \& Morsomme, 2014; Studer, Gomez, Hildebrandt, Arial, \& Danuser, 2011). An earlier survey by Fishbein, Middlestadt, Ottati, Straus, and Ellis (1988) indicated that MPA was the most common problem among professional orchestral musicians, with women experiencing it more severely and frequently than men.

Performance anxiety may begin in the early stages of learning music (Boucher \& Ryan, 2011), often in response to a sensitizing performance experience (Osborne \& Kenny, 2008). The level of MPA is reported to be higher in solo performances compared with playing in a group setting (Fancourt, Aufegger, \& Williamon, 2015; Nicholson, Cody, \& Beck, 2015) although student ensemble musicians have also been shown to suffer from severe MPA (Robson \& Kenny, 2017). Kenny (2009a) has proposed a definition of MPA as follows:

\footnotetext{
Music performance anxiety is the experience of marked and persistent anxious apprehension related to musical performance that has arisen through specific anxiety conditioning experiences and which is manifested through combinations of affective, cognitive, somatic and behavioral symptoms. It may occur in a range of performance settings, but is usually more severe in settings involving high ego investment and evaluative threat. It may be focal (i.e. focused only on music performance), or occur co-morbidly with other anxiety disorders, in particular social phobia. It affects musicians across the lifespan and is at least partially independent of years of training, practice and level of musical accomplishment. It may or may not impair the quality of the musical performance. (p. 433)
}

This definition has superseded previous definitions that have been shown to be inconsistent with prevailing and subsequent research about the nature of MPA (e.g., Lederman, 1999; Salmon, 1990). MPA is understood to be a multidimensional construct with psychological (emotional), physiological, cognitive, and behavioral components; while minor stress before going on stage may be normal and does not necessarily lead to an impairment of the performance, some musicians experience a level of anxiety such that it interferes with the quality of their performance and may have other harmful consequences.

Intense fear provoked by a public performance is often conditioned by previous negative experiences (Kenny, 2011; Osborne, Kenny, \& Cooksey, 2007). Psychologically demanding situations like auditions or recitals in an unfamiliar environment may provoke physiological symptoms of stress (Braden, Osborne, \& Wilson, 2015; Osborne, Greene, \& Immel, 2014; Patston, 2014). Previous studies emphasized the role of negative emotions (fear, anxiety) in the development of MPA (Kenny, 2009b). Since seeking professional help is often undermined by the fear of being judged, it makes the prevalence and background of MPA hard to clarify. However, some studies 
showed that MPA was often co-morbid with disorders such as social phobia (Kenny et al., 2014; Osborne \& Kenny, 2008). Significant distress and feeling anxious in situations when one's performance is likely to be evaluated by others led to a conclusion that MPA might be a specific form of social phobia (Barlow, 2000, 2002; Kenny, 2006; Osborne \& Kenny, 2005).

Although currently MPA is not a separate disorder, performance anxiety has been mentioned in the differential diagnosis of social phobia in the Diagnostic and Statistical Manual of Mental Disorders (5th ed.; DSM-5; American Psychiatric Association [APA], 2013, p. 203). According to previous research, the prevalence of specific phobia $(12.5 \%)$ and social phobia $(12.1 \%)$ is the highest for all age groups among anxiety disorders (see Kessler et al., 2005, p. 596). Social phobias usually develop during early adolescence, yet despite experiencing serious impairments, patients rarely seek treatment (Magee, Eaton, Wittchen, McGonagle, \& Kessler, 1996). The median age of onset is 13 years, with $75 \%$ of individuals experiencing their first symptoms between 8 and 15 years (APA, 2013, p. 205). If the fear or anxiety experienced by the individual is restricted only to public speaking and performing, and does not affect any other social situation, it can be specified as "performance-only" type of social anxiety disorder (social phobia). Social phobics" focus is particularly on the "self", and worrying about one's somatic symptoms (e.g., sweating, blushing) when being observed by others. Two characteristic traits that individuals with social phobia often display are self-focused attention and fear of negative evaluation. In social phobia, different external social cues are processed in a reduced way and this leads to a "distorted, negative impression of one's observable self" (Clark, 2001, p. 410).

In relation to performance settings (solo, group, and practice), social anxiety is a significant predictor of MPA in each setting (Nicholson et al., 2015). Negative responses during performance can cause depressive tendencies (Bannai, Kase, Endo, \& Oishi, 2016) which renders musicians with higher MPA at greater risk of co-morbid anxiety and/or mood disorders. Using a clinical assessment tool (the CIDI-A, which uses DSM-IV criteria), Osborne and Franklin (2002) reported that $27 \%$ of musicians with high MPA were also diagnosed with social phobia; the rate was $41 \%$ using ICD-10 criteria. Similarly, Osborne and Kenny (2005) demonstrated a significant overlap between peak MPA and social anxiety in an adolescent sample (average age 15 years). In a study by Barbar, Crippa, and Osório (2014) 24\% of adult musicians had indicators of MPA; $29 \%$ of musicians with MPA had social anxiety (43\%) and depression (48\%). Similar to previous findings, in a sample of Australian musicians, 33\% met the criteria of social anxiety disorder, $32 \%$ had depression, and $22 \%$ reported some symptoms associated with posttraumatic stress disorder (Ackermann et al., 2014).

Notwithstanding the apparent high levels of co-morbidity between MPA and social anxiety, the relationship between MPA and social anxiety may not be as synchronous as first assumed. Indeed, Kenny (2011) discussed the debate in the literature as to whether MPA represents a form of social phobia. Some researchers argue that both conditions are centrally organized around fear of negative evaluation (Barlow, 2002; Wilson, 2002), while others argue that performance anxiety may be part of a larger constellation of symptoms representing social anxiety disorder (Hook \& Valentiner, 2002; Turner, Johnson, Beidel, Heiser, \& Lydiard, 2003). The classification of social phobia into generalized (i.e., anxiety experienced about interpersonal interactions generally), non-generalized (i.e., anxiety experienced only in settings in which the individual is being scrutinized), and specific (i.e., anxiety is reserved for very few performance situations) sub-types (Turner et al., 2003) may assist in the clarification of music performance anxiety as a form of the specific social anxiety sub-type. This specific sub-type may be equivalent to music performance anxiety as a focal anxiety disorder if music performance under conditions of threat or scrutiny is the only situation in which anxiety symptoms are manifested. 
In addition, Kenny (2011) has documented reliable differences between performance anxiety and social anxiety. Those with performance anxiety are more likely than those with social anxiety to have higher expectations of themselves (Abbott \& Rapee, 2004); greater fear of their own evaluation of their performance, as opposed to fear of the scrutiny of others in social anxiety (Stoeber \& Eismann, 2007), although the latter is also present in MPA; a higher degree of post-event rumination (Abbott \& Rapee, 2004); and a continued commitment to the feared performance situation, as opposed to avoidance of, or escape from the feared situation in social phobia (Powell, 2004). Further, in social phobia, the feared task is not usually cognitively or physically demanding and is usually already in the behavioral repertoire of the person with social anxiety; that is, social anxiety is not generally associated with social or behavioral skills deficits (Hofmann, Gerlach, Wender, \& Roth, 1997). Musical performance, on the other hand, requires complex skill acquisition, intensive practice, mental and physical rehearsal, coordination, and great demands on cognitive capacity and memory. Performance anxiety may also be associated with failure of task mastery (Wilson, 2002) or attempts to perform tasks that exceed the capacity of the performer (Fehm \& Schmidt, 2006), circumstances that are rarely present in social anxiety. It is therefore an over-simplification to characterize social anxiety and MPA as the same condition and more research needs to be undertaken to determine whether the disparate characteristics between social anxiety and MPA are both in evidence in anxious musicians. Therefore, there is a need to further clarify whether musicians experience social anxiety beyond performance settings (e.g., talking with strangers or superiors).

An important personality disposition in the background of MPA is perfectionism, which may co-occur in both performance anxiety and social phobia. Perfectionist cognitions include setting unrealistically high standards for performance, for example, striving for the "perfect" performance and having a constant need to be perceived as flawless (Flett, Hewitt, Oliver, \& Macdonald, 2002; Frost, Marten, Lahart, \& Rosenblate, 1990). There is a correlation between MPA and perfectionism with both showing an increasing tendency over the years of learning music (Kenny, 2011; Patston \& Osborne, 2016). Several studies have reported high levels of perfectionism in adult musicians (Patston, 2010, 2014; Sinden, 1999).

Perfectionism makes an individual vulnerable to a number of mental health conditions (Oddo-Sommerfeld, Hain, Louwen, \& Schermelleh-Engel, 2015). For example, perfectionist traits have been associated with anxiety, depression, eating, and personality disorders (Flett, Hewitt, Blankstein, \& Gray, 1998; Hewitt et al., 2003; Stoeber, Madigan, Damian, Esposito, \& Lombardo, 2016). The development of perfectionism commences in early childhood with family and cultural environments being important factors (Flett et al., 2002). Psychological control exerted by parents predicts an increase in maladaptive perfectionism, that in turn causes a vulnerability to depressive symptoms (Soenens et al., 2008).

Perfectionism has been poorly evaluated in musicians, although studies have supported the relationship between perfectionism and MPA (and social phobia or other mental health problems). Perfectionism is a multi-dimensional construct involving dimensions such as high concern over mistakes, high doubts about actions and low personal standards. Frost et al. (1990) therefore suggested a multidimensional approach to its examination because there may be differences in the role of different dimensions, for example, believing that others have unrealistic expectations about one's performance (particularly significant others, such as parents) or one's own unrealistic expectations. Likewise, differences may stem from criticism, doubts or setting personal standards.

Mor, Day, Flett, and Hewitt (1995) investigated perfectionism in 49 professional classical musicians and found that performers with higher personal standards of perfection (e.g., "I must work to my full potential at all times") and social standards of perfection (e.g., "The people 
around me expect me to succeed at everything I do") experienced more debilitating anxiety than those performers who did not score highly on these items. Another study, using the Frost Multidimensional Perfectionism Scale on a sample of 138 university instrumental music students, reported a significant relationship between some dimensions of perfectionism and performance anxiety (Sinden, 1999). In a subsequent study, Kawamura, Hunt, Frost, and DiBartolo (2001) found that maladaptive perfectionism was related to a social/trait anxiety/worry factor. Concern over mistakes as a dimension of perfectionism was also found to be an important component of MPA (Kenny et al., 2004; Patston, 2014). Dimensions of perfectionism do not play the same role in MPA - there may be differences due to age, gender or other characteristics (Patston \& Osborne, 2016).

Based on the literature review, the interaction of MPA, perfectionism, and social anxiety may play a role in maintaining performance anxiety (Kenny, 2011). However, previous research also suggests that there are some unrecognized aspects of these relationships. First, despite the apparent high levels of co-morbidity between MPA and social anxiety, the relationship is not entirely synchronous, particularly in the light of perfectionism. Furthermore, we know less about the relationship between dimensions of perfectionism and MPA, such as how this might influence performance quality. Individuals with performance-only social anxiety disorders do not fear non-performance social situations (APA, 2013, p. 203). Having fear in a variety of social interactions would make MPA more than just performance-only type social anxiety disorder.

Therefore, the main goals of the current study were the following: 1) to obtain preliminary information about MPA in a sample of Hungarian musicians and music students; 2) to detect interrelationships among (general) social anxiety, perfectionism and MPA, both bi-directionally and in multivariate analysis; 3 ) to analyze the role of different dimensions of perfectionism in MPA; and 4) to detect whether substance use (particularly anxiolytic medication) might be associated with MPA. Based on the main goals and the literature, the following hypotheses were developed: 1) As in previous research, female students will have higher levels of MPA than male students; 2) musicians will be more likely to experience anxiety in social situations that do not require musical performance; 3 ) social anxiety will be related to perfectionism and MPA; 3) different dimensions of perfectionism will have differential effects on MPA; and 4) use of anxiolytic medication will be prevalent in those with a co-morbid social anxiety.

\section{Methods}

\section{Participants}

The sample consisted of early career (graduate) musicians and music students $(N=100 ; 38 \%$ males and $62 \%$ females, aged between $15-35$ years, with a mean age of 23 years, $S D=9.8$ ). They had been training for an average 14.9 years $(S D=9.8)$ with length of their weekly practice of 13.5 hours $(S D=10.1)$. The sample was characterized by the following types of music: $77 \%$ classical music, $15 \%$ pop music, $4 \%$ folk, and $4 \%$ jazz music. The following instruments and music-related job activities were mentioned: strings (31\%), woodwinds (22\%), keyboard $(21 \%)$, vocal $(13 \%)$, brass $(7 \%)$, percussion $(3 \%)$, and music theory $(3 \%)$.

\section{Procedure}

After receiving ethical approval from the Institutional Review Board of the Doctoral School, University of Szeged, data were collected via online survey by means of different social 
networking sites (e.g., Facebook groups). An anonymous, self-reported questionnaire was used as a method of data collection. Participation was voluntary and the participants agreed that completion and return of the questionnaire was construed as consent.

\section{Measures}

The questionnaire contained items on socio-demographics (age, gender), practice-related activities (years of learning music, hours of weekly practice), health-related behaviors (smoking, illicit drug use, anxiolytic medication), music performance anxiety, social phobia, and perfectionism. The scales were translated and back-translated by bilingual translators.

The following scales were used:

(1) Kenny Music Performance Anxiety Inventory (K-MPAI: Kenny, 2009a). This 40-item inventory was developed to assess the emotion-based theory of anxiety proposed by Barlow (2000) as this scale was applied to anxiety in the context of music performance. The items implied cognitive, behavioral, and somatic characteristics of anxiety. The responses were measured on a 7 -point Likert-type scale $(0=$ Strongly disagree to $6=$ Strongly agree). Higher scores indicated greater anxiety and psychological distress. The scale demonstrated excellent internal reliability with the current sample (Cronbach's $\alpha=0.93)$.

(2) Frost Multidimensional Perfectionism Scale (FMPS: Frost et al., 1990). This is a 35-item questionnaire designed to measure six dimensions of perfectionism: Concern over Mistakes (CM), Doubts about Actions (DA), Personal Standards (PS), Parental Expectations (PE), Parental Criticism (PC), and Organization $(\mathrm{O})$. Responses were scored on a 5 -point Likert-type scale $(1=$ Strongly disagree to $5=$ Strongly agree $)$. Higher scores indicated higher tendencies to perfectionism. Cronbach's $\alpha$ value of reliability for the whole scale was .92, whereas the coefficients for the subscales varied between 0.75 $(\mathrm{DA}=$ Doubts about Actions) and $0.89(\mathrm{CM}=$ Concern over Mistakes; $\mathrm{O}=$ Organization $)$.

(3) Social Phobia Inventory (SPIN: Connor, Davidson, Churchill, Sherwood, \& Weisler, 2000). This 17-item self-report inventory evaluates the full spectrum of symptoms of non-specific social phobia including fear, avoidance, and physiological symptoms. Answers were scored on a 5-point Likert-type scale from 0 representing "not at all" to 4 representing "extremely". The SPIN has demonstrated good properties to differentiate adolescents with SP (social phobia) and those with sub-clinical SP symptoms (SSP), from adolescents without SP in previous studies (Crippa et al., 2008). The SPIN also differentiates adolescents with SP from those with depressive and disruptive disorders (Crippa et al., 2008). The SPIN has also been effective for screening and identification of adolescent SP (Crippa et al., 2008). In a sample of 802 adolescents, good test-retest reliability ( $r=0.81)$ and internal consistency (alpha $=0.89$ ) were found for the SPIN (Ranta et al., 2007). The total score ranged from 0 to 68 , with a diagnostic accuracy of $79 \%$ (Connor et al., 2000). A cut-off score of 20 was used to distinguish the social phobia subjects from the nonsocial phobia controls. Cronbach's $\alpha$ was 0.92 with the current sample.

\section{Results}

Descriptive statistics (values for minimum, maximum, means and standard deviations) for Music Performance Anxiety Inventory, Social Phobia Inventory, and dimensions of Multidimensional Perfectionism Scale are presented in Table 1. Gender differences were detected 
Table 1. Descriptive statistics for Music Performance Anxiety Inventory, Social Phobia Inventory, and dimensions of Multidimensional Perfectionism Scale $(N=100)$.

\begin{tabular}{lcccrr}
\hline & Minimum & Maximum & \multicolumn{1}{l}{$M(S D)$} & \multicolumn{1}{l}{$\begin{array}{l}\text { Males } \\
M(S D)\end{array}$} & \multicolumn{1}{c}{$\begin{array}{l}\text { Females } \\
\text { M SD })\end{array}$} \\
\hline K-MPAI** $^{*}$ & 30 & 184 & $93.5(38.0)$ & $78.1(33.7)$ & $103.0(37.0)$ \\
SPIN $^{* * *}$ & 0 & 60 & $20.5(14.2)$ & $14.3(10.3)$ & $24.3(15.0)$ \\
FMPS & 35 & 160 & $107.8(22.4)$ & $105.1(22.2)$ & $109.6(22.5)$ \\
CM $^{*}$ & 9 & 44 & $24.6(9.1)$ & $22.2(9.0)$ & $26.1(8.8)$ \\
PS & 7 & 35 & $25.6(5.5)$ & $26.1(5.4)$ & $25.2(5.5)$ \\
PE & 5 & 24 & $12.3(5.4)$ & $11.8(5.1)$ & $12.7(5.6)$ \\
PC & 4 & 20 & $8.7(4.1)$ & $8.6(3.6)$ & $8.8(4.4)$ \\
DA $^{\#}$ & 4 & 20 & $13.1(3.9)$ & $12.2(3.9)$ & $13.6(3.7)$ \\
O $^{*}$ & 6 & 30 & $23.6(4.6)$ & $24.3(4.0)$ & $23.2(4.9)$ \\
\hline
\end{tabular}

Note. $\mathrm{K}-\mathrm{MPAI}=$ Music Performance Anxiety Inventory; SPIN $=$ Social Phobia Inventory; FMPS $=$ Frost Multidimensional Perfectionism Scale; $\mathrm{CM}=$ Concern over Mistakes; $\mathrm{PS}=$ Personal Standards; $\mathrm{PE}=$ Parental Expectations; $\mathrm{PC}=$ Parental Criticism; $\mathrm{DA}=$ Doubts about Actions; $\mathrm{O}=$ Organization .

${ }^{*} p<.05 .{ }^{* *} p<.01 .{ }^{* * *} p<.001 .{ }^{*} p=.07$.

Table 2. Lifetime and monthly prevalence (\%) of health-related behaviors $(N=100)$.

\begin{tabular}{llc}
\hline & Lifetime prevalence (\%) & Monthly prevalence (\%) \\
\hline Smoking & & 31 \\
$\quad$ Yes & 59 & 69 \\
$\quad$ No & 41 & \\
Illicit drug & & 7 \\
$\quad$ Yes & 24 & 93 \\
$\quad$ No & 76 & 7 \\
Anxiolytic medication & 28 & 93 \\
$\quad$ Yes & 72 & \\
No & & \\
\hline
\end{tabular}

in levels of MPA: $t(98)=-3.38, p<.01$.; social phobia: $t(98)=-3.64, p<.001$; and the Concern over Mistakes subscale of perfectionism: $t(98)=-2.10, p<.05$. All these scales showed higher scores among female musicians.

Table 2 presents lifetime and monthly prevalence of some health-related behaviors, namely, cigarette and illicit drug consumption, and use of anxiolytic medication: $41 \%$ of the participants had never smoked, 69\% had not smoked during the past month; $7 \%$ reported drug consumption (e.g., marijuana or ecstasy) in the past month, whereas $76 \%$ reported that they had never used an illicit substance; $28 \%$ of the musicians had taken anxiolytic medication, $7 \%$ in the past month.

Table 3 shows correlation coefficients for bivariate relationships between socio-demographics and music and health-related variables and the scales. Among socio-demographics, there was a negative correlation between age and weekly hours of practice. Gender (being female) was negatively correlated with smoking and drug use but positively associated with anxiolytic medication, MPA $(r=.32 ; p<.01)$, and social phobia $(r=.34 ; p<.001)$. Years spent in music training was negatively correlated with social phobia $(r=-.198 ; p<.05)$. MPA was positively 


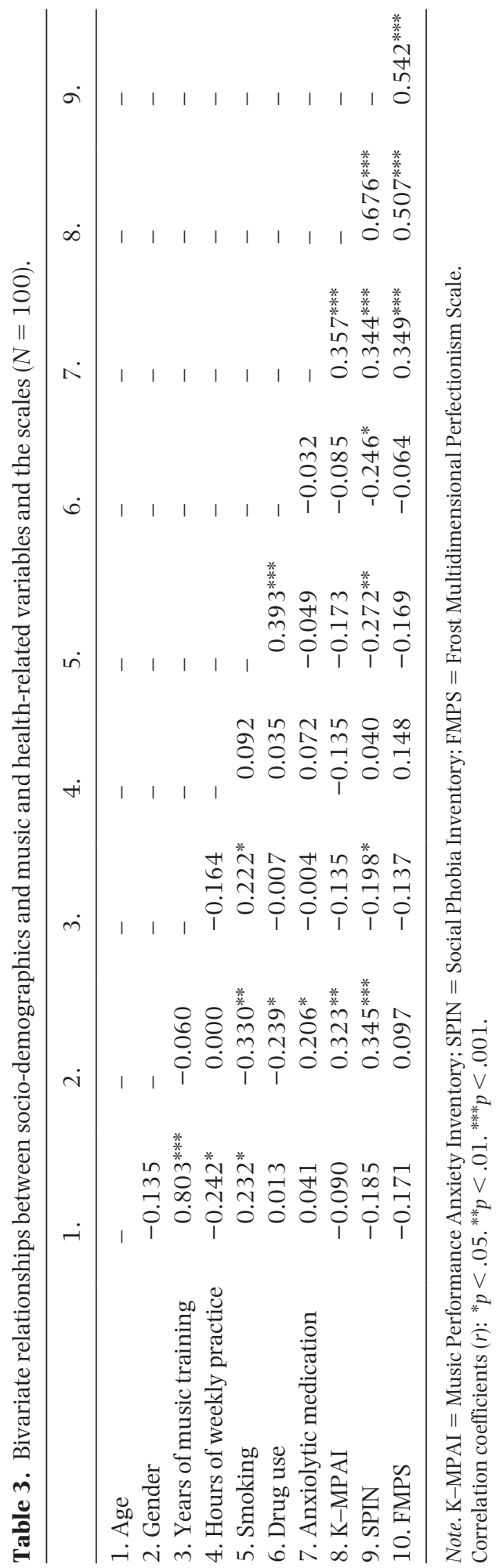


Table 4. Bivariate relationships between the scales for music performance anxiety, social phobia, and dimensions of perfectionism $(N=100)$.

\begin{tabular}{llllllll}
\hline & 1. & 2. & 3. & 4. & 5. & 6. & 7. \\
\hline 1. K-MPAI & - & - & - & - & - & - & - \\
2. SPIN & $0.676^{* * *}$ & - & - & - & - & - & - \\
3. CM & $0.591^{* * *}$ & $0.614^{* * *}$ & - & - & - & - & - \\
4. PS & $0.235^{*}$ & $0.338^{* *}$ & $0.618^{* * *}$ & - & - & - & - \\
5. PE & $0.243^{*}$ & $0.335^{* *}$ & $0.395^{* * *}$ & $0.243^{*}$ & - & - & - \\
6. PC & $0.346^{* * *}$ & $0.249^{*}$ & $0.385^{* * *}$ & $0.249^{*}$ & $0.761^{* * *}$ & - & - \\
7. DA & $0.681^{* * *}$ & $0.549^{* * *}$ & $0.645^{* * *}$ & $0.481^{* *}$ & $0.284^{* *}$ & $0.313^{* *}$ & - \\
8. O & -0.143 & -0.054 & 0.070 & $0.311^{* *}$ & 0.085 & 0.083 & 0.07 \\
\hline
\end{tabular}

Note. $\mathrm{K}-\mathrm{MPAI}=$ Music Performance Anxiety Inventory; SPIN = Social Phobia Inventory; FMPS = Frost Multidimensional Perfectionism Scale; $\mathrm{CM}=$ Concern over Mistakes; PS = Personal Standards; $\mathrm{PE}=$ Parental Expectations; $\mathrm{PC}=$ Parental Criticism; $\mathrm{DA}=$ Doubts about Actions; $\mathrm{O}=$ Organization .

Correlation coefficients $(r):{ }^{*} p<.05 .{ }^{* *} p<.01 .{ }^{* *} p<.001$.

associated with anxiolytic medication $(r=.36 ; p<.001)$ but this latter variable was also correlated with social phobia $(r=.34 ; p<.001)$ and perfectionism $(r=.35 ; p<.001)$. While there were negative correlations between social phobia and the health-related variables, smoking and drug use were not significantly correlated with MPA. All these were relatively weak correlations. Finally, there were moderate to strong inter-correlations among MPA, social phobia, and perfectionism (correlation coefficients were between $r=.34$ and $.67, p<.001$ ).

Different dimensions (subscales) of perfectionism were used to calculate bivariate relationships between MPA and the other psychological scales (Table 4). Among the six subscales of perfectionism, five showed a positive correlation with MPA and social phobia. In terms of the relationships with MPA, a relatively strong association could be detected with DA $(r=.68$; $p<.001)$ and $\mathrm{CM}(r=.59 ; p<.001)$. A similar strong correlation was observed between social phobia and $\mathrm{CM}(r=.61, p<.001)$ and DA $(r=.55 ; p<.001)$. Among the subscales, Organization (O) was correlated only with Personal Standards (PS) $(r=.31 ; p<.01)$.

Finally, Table 5 presents results of the hierarchical regression models detecting predictors of MPA using different regression models. In Model 1, besides socio-demographics (gender, age), practice-related variables and anxiolytic medication (that was significantly correlated with MPA in bivariate analysis) were involved (i.e., behavioral variables). In Model 2, psychological scales are also added where socio-demographics and behavioral variables were controlled for. Finally, in Model 3, each subscale of perfectionism was tested besides the other variables. In Model 1, gender was positively related to the dependent variable $(\beta=.24 ; p<.01)$. A similar relationship was also observed in the case of anxiolytic medication $(\beta=.32 ; p<.001)$, whereas weekly hours of practice showed a negative association $(\beta=-.18 ; p<.05)$. In Model 2 , only this latter variable remained significant along with the psychological scales (social phobia: $\beta=.48 ; p<.001$; perfectionism: $\beta=.22 ; p<.05)$. Both models were significant: the first explained $24 \%$, the second one explained $54 \%$ of the variance. In Model 3, instead of the total score of the perfectionism scale, subscales were included. Among these subscales, $\operatorname{PE}(\beta=-.19$; $p<.05)$ and $\mathrm{O}(\beta=-.13 ; p<.05)$ were negative contributors, whereas $\mathrm{PC}(\beta=.23 ; p<.05)$ and DA $(\beta=.44 ; p<.001)$ were positively associated with MPA. In this model, only social phobia remained significant $(\beta=.35 ; p<.001)$. All together these variables explained $71 \%$ of the variance. 
Table 5. Hierarchical multiple regression models for music performance anxiety (K-MPAI).

\begin{tabular}{lccr}
\hline Variables & Model 1 & Model 2 & \multicolumn{1}{c}{ Model 3 } \\
& $\beta(S E)$ & $\beta(S E)$ & $\beta(S E)$ \\
\hline Gender & $0.24(7.11)^{* *}$ & $0.11(5.89)$ & $0.06(5.08)$ \\
Years of music training & $-0.15(0.35)$ & $-0.03(0.28)$ & $-0.04(0.24)$ \\
Hours of weekly practice & $-0.18(0.34)^{*}$ & $-0.20(0.27)^{* *}$ & $-0.12(0.24)$ \\
Anxiolytic medication & $0.32(4.63)^{* * *}$ & $0.11(3.90)$ & $0.12(3.39)$ \\
SPIN & & $0.48(0.24)^{* * *}$ & $0.35(0.22)^{* * *}$ \\
FMPS & & & $0.12(0.42)$ \\
FMPS_CM & & & $-0.13(0.62)$ \\
FMPS_PS & & & $-0.19(0.66)^{*}$ \\
FMPS_PE & & & $0.23(0.89)^{*}$ \\
FMPS_PC & & & $0.44(0.81)^{* * *}$ \\
FMPS_DA & & & $-0.13(0.53)^{*}$ \\
FMPS_O & & & $45.8^{*}$ \\
Constant & & & $0.71^{* * *}$ \\
$R^{2}$ & $0.24^{* * *}$ & $0.54^{* * *}$ & \\
\hline
\end{tabular}

Note. $\mathrm{K}-\mathrm{MPAI}=$ Music Performance Anxiety Inventory; SPIN = Social Phobia Inventory; FMPS = Frost Multidimensional Perfectionism Scale; $\mathrm{CM}=$ Concern over Mistakes; PS = Personal Standards; PE = Parental Expectations; $\mathrm{PC}=$ Parental Criticism; DA = Doubts about Actions; $\mathrm{O}=$ Organization .

Standardized regression coefficient $(\beta):{ }^{*} p<.05 .{ }^{* *} p<.01 .{ }^{* * *} p<.001$.

Table 6. Collinearity diagnostics of the multiple linear regression models for music performance anxiety.

\begin{tabular}{|c|c|c|c|}
\hline & Model 1 & Model 2 & Model 3 \\
\hline & Tolerance (VIF) & Tolerance (VIF) & Tolerance (VIF) \\
\hline Gender & $0.95(1.05)$ & $0.85(1.17)$ & $0.78(1.28)$ \\
\hline Years of music training & $0.97(1.03)$ & $0.93(1.07)$ & $0.85(1.17)$ \\
\hline Hours of weekly practice & $0.97(1.03)$ & $0.95(1.05)$ & $0.82(1.22)$ \\
\hline Anxiolytic medication & $0.95(1.05)$ & $0.82(1.22)$ & $0.74(1.35)$ \\
\hline SPIN & & $0.59(1.70)$ & $0.49(2.00)$ \\
\hline FMPS & & $0.65(1.55)$ & \\
\hline FMPS_CM & & & $0.36(2.70)$ \\
\hline FMPS_PS & & & $0.41(2.40)$ \\
\hline FMPS_PE & & & $0.39(2.50)$ \\
\hline FMPS_PC & & & $0.38(2.50)$ \\
\hline FMPS_DA & & & $0.54(1.84)$ \\
\hline FMPS_O & & & $0.81(1.24)$ \\
\hline
\end{tabular}

Note. VIF $=$ Variance Inflation Factor. SPIN = Social Phobia Inventory; FMPS = Frost Multidimensional Perfectionism Scale; $\mathrm{CM}=$ Concern over Mistakes; $\mathrm{PS}=$ Personal Standards; $\mathrm{PE}=$ Parental Expectations; $\mathrm{PC}=$ Parental Criticism; $\mathrm{DA}=$ Doubts about Actions; $\mathrm{O}=$ Organization.

The reliability of the model was further examined with VIF (Variance Inflation Factor) indices and tolerance values (Table 6). For Model 1 and Model 2, the VIF values fell within the optimal VIF range $(<2)$, indicating that multicollinearity was not present in the subscales of 
the Perfectionism questionnaire (FMPS). Model 3 yielded moderate correlations $(<5)$ between subscales of the perfectionism construct. However, since they did not reach the unacceptable range $(>10)$, the overall reliability of our model seems capable.

\section{Discussion}

Despite its relevance in the international literature, music performance anxiety is a greatly under-explored field in Hungary. In this study, we obtained some baseline information about MPA in Hungarian musicians, but we were primarily concerned with the interrelationship among MPA, social phobia, and perfectionism.

Consistent with Kenny's definition of MPA, there was no association between age, years of training as a musician, or amount of practice. Our results supported previous findings that females are more likely to develop anxiety disorders and report more MPA than male musicians (Fishbein et al., 1988; Kenny et al., 2014; Ginsberg, 2004). In our study female musicians scored significantly higher on the MPA measure (K-MPAI-R). Thus, our first hypothesis was confirmed. Gender differences were also found for social phobia: females had significantly higher scores on social phobia (SPIN) than males. In previous studies women were twice as likely to be affected by anxiety disorders than men (Furmark et al., 1999; Kringlen, Torgersen, \& Cramer, 2001). Although no significant gender differences were found for the total score of perfectionism (FMPS), females scored higher on the subscale of Concern over Mistakes (CM).

Based on previous findings (Gorges, Alpers, \& Pauli, 2007; Kenny, 2006) we tested the association between MPA and non-performance related social phobia. Consistent with previous research (Osborne \& Kenny, 2005, 2008), we found a strong positive association between MPA and social phobia. This finding supports our second hypothesis. However, the role of perfectionism - which is linked with automatic thoughts, anxiety, and irrational fears (Blankstein, Flett, Hewitt, \& Eng, 1993; Flett, Greene, \& Hewitt, 2004) —in social anxiety is less clear. Social phobics tend to avoid social contact and do not set high expectations for themselves (Alden, Ryder, \& Mellings, 2002). Examining this relationship, Juster et al. (1996) found that social phobia patients scored higher on three subscales (CM, DA and PC) of perfectionism which caused greater social and trait anxiety. Our findings supported these associations.

One of the main goals of the paper was to achieve a deeper insight into these interrelationships; therefore, we included all six dimensions of perfectionism in the analyses. Five dimensions were inter-correlated; the exception was Organization $(\mathrm{O})$, which showed a modest correlation only with Personal Standards (PS). The social phobia measure (SPIN) demonstrated a moderate to strong positive correlation with five out of six subscales of perfectionism. The association was strongest for Concern over Mistakes (CM) and Doubts about Actions (DA). People with social anxiety tend to process information differently and are more sensitive to other people's behavior (emotional state, facial expressions) which is commonly referred to as "hyperscanning" (Boll, Bartholomaeus, Peter, Lupke, \& Gamer, 2016). This heightened sensitivity for social cues, combined with the trait of perfectionism increases perception of both perceived and real threats. We assume that, given a choice, social phobics would rather avoid a socially threatening situation, but avoidance interferes with a need to excel in musicians, thus creating enormous intrapersonal tension.

The total perfectionism scale (FMPS) had a moderately strong correlation with the total score of K-MPAI. This finding is similar to the study which examined three dimensions of perfectionism. Musicians with higher self-related and socially prescribed perfectionism scores experienced debilitating performance anxiety (Mor et al., 1995). These factors were also 
significant in predicting MPA in the regression analysis. Correlation and regression analyses suggested that different dimensions of perfectionism may play different roles in MPA. These findings support our third hypothesis. For example, in line with existing literature on perfectionist concerns the subscale Parental Criticism (PC) predicted higher MPA (Damian, NegruSubtirica, Stoeber, \& Băban, 2016). This dimension measures overly critical parenting that is associated with punishment of any result that is less than perfect (Frost et al., 1990). Lack of family support due to parental criticism leads to insecurity, distress, and possibly anxious performance (Kenny, 2011; Ringeisen \& Raufelder, 2015). On the other hand, ParentalExpectations (PE) reflect a belief that one's parents set high standards and not living up to them would leave parents unsatisfied or disappointed (Frost et al., 1990). In our study, parental expectations did not contribute to MPA; indeed, the reverse was true. It is possible that having parents who expect only the best results provides motivation that does not necessarily lead to MPA. On the contrary, PE may give encouragement and strength to overcome stressful life events provided that the level of expectation is consistent with the capacity to achieve at that level. One study of much younger musicians than those reported here, found a positive relationship between parental expectations and MPA (Patston \& Osborne, 2016). For late adolescents and youth, the role of parents can be different. A longitudinal study found that perceived parental expectations do not predict self-oriented perfectionism; however, it predicts an increase in socially prescribed perfectionism (Damian, Stoeber, Negru, \& Băban, 2013). There are also possible cultural characteristics in Eastern Europe where traditional, authoritarian parenting is still accepted. More investigation is needed to further clarify this issue.

Likewise, Organization $(\mathrm{O})$ in this concept of perfectionism was also a negative predictor of MPA. An organized person generally feels comfortable and more in control over one's own actions. Being able to concentrate and believing in one's power to overcome negative circumstances is the opposite of being anxious. Controlling some aspects of life can be a coping mechanism that helps to deal with anxiety. Our findings suggest that unlike criticism, the need to be organized does not necessarily lead to having more performance anxiety. Contrary to the misconception that perfectionism can play only a negative role in performance anxiety, some dimensions of perfectionism may actually help to reduce MPA. Our findings support Stoeber and Otto's (2006) theory that perfectionism can be both positive and negative, and highlight the value of more nuanced understandings of the role perfectionism plays in MPA (Stoeber \& Otto, 2006). These findings may contribute to establishing new and more differentiated approaches to perfectionism. Namely, certain aspects of perfectionism may increase/intensify performance anxiety while others may lower it.

Anxiety disorders and substance abuse are often co-morbid (Meaney, Liebowitz, \& David Leonardo, 2015). Smoking and illicit drug use were correlated with social phobia, but were not significant predictors of MPA severity, suggesting that for some musicians, these substances are lifestyle choices, or attempts to manage social anxiety, rather than attempts to manage their MPA. Substance abuse could also be associated with the higher levels of overall self-care displayed by musicians (Kenny et al., 2004). The prevalence of smoking and drug use was similar to previous data collected from musicians internationally (Miller \& Quigley, 2011). According to a recent study, anxiety disorders (depression, social anxiety, panic disorder) are more common among current smokers (Goodwin et al., 2014). Over 30\% of musicians reported smoking in the past month, compared with $17 \%$ of adults aged 19-30 years (Johnston, O'Malley, Bachmann, \& Schulenberg, 2009). On the other hand, the percentage of musicians taking anxiolytic medication was higher $(28 \%)$ than in other studies and it was associated with MPA. Thus, this hypothesis has also been confirmed. According to Kenny, Driscoll, \& Ackermann (2014), beta-blockers were used by $31 \%$ of orchestral musicians while $4.9 \%$ used other anti-anxiety medication. In a 
Brazilian study $27.8 \%$ of musicians reported the use of medications but only $2.6 \%$ reported the use of anxiolytic medication or antidepressants (Barbar et al., 2014).

Limitations include the small sample size of Hungarian musicians and the fact that data were collected via online survey (and not based on a representative sampling) using only screening tools rather than diagnostic instruments. We were not able to clarify whether the purpose of taking anxiolytic medication was to reduce symptoms of MPA or for any other condition, or if it was prescribed by a physician. Additional research with larger samples of musicians is required to investigate the role of dimensions of perfectionism that may be responsible for enhancing, maintaining or reducing MPA.

Finally, based on the findings we can conclude that music performance anxiety is complex and multi-factorial, with possible early onset. We believe these findings may contribute to better understanding of young musicians' fear and anxiety and its possible contributors, thus alerting parents, teachers, and mental health professionals to the value of early recognition, management, and intervention.

\section{Funding}

This research received no specific grant from any funding agency in the public, commercial, or not-forprofit sectors.

\section{References}

Abbott, M. J., \& Rapee, R. M. (2004). Post-event rumination and negative self-appraisal in social phobia before and after treatment. Journal of Abnormal Psychology, 113(1), 136-144. doi: 10.1037/0021$843 x .113 .1 .136$

Ackermann, B. J., Kenny, D. T., O’Brien, I., \& Driscoll, T. R. (2014). Sound practice: Improving occupational health and safety for professional orchestral musicians in Australia. Frontiers in Psychology, 5(973). doi: 10.3389/fpsyg.2014.00973

Alden, L. E., Ryder, A. G., \& Mellings, T. M. B. (2002). Perfectionism in the context of social fears: Toward a two-component model. In G. L. Flett \& P. L. Hewitt (Eds.), Perfectionism: Theory, research, and treatment (pp. 373-391). Washington, DC: American Psychological Association. doi: 10.1037/10458-015

American Psychiatric Association (APA). (2013). Diagnostic and statistical manual of mental disorders (5th ed.). Washington, DC: Author. doi: 10.1176/appi.books.9780890425596

Bannai, K., Kase, T., Endo, S., \& Oishi, K. (2016). Relationships among performance anxiety, agari experience, and depressive tendencies in Japanese music students. Medical Problems of Performing Artists, 31(4), 205-210. doi: 10.21091/mppa.2016.4037

Barbar, A. E. M., Crippa, J. A., \& Osório, F. (2014). Performance anxiety in Brazilian musicians: Prevalence and association with psychopathology indicators. Journal of Affective Disorders, 152, 381-386. doi: 10.1016/j.jad.2013.09.041

Barlow, D. H. (2000). Unravelling the mysteries of anxiety and its disorders from the perspective of emotion theory. American Psychologist, 55(11), 1247-1263. doi: 10.1037//0003-066x.55.11.1247

Barlow, D. H. (2002). Anxiety and its disorders: The nature and treatment of anxiety and panic. New York, NY: Guilford Press.

Bartel, L. R., \& Thompson, E. G. (1994). Coping with performance stress: A study of professional orchestral musicians in Canada. The Quarterly Journal of Music Teaching and Learning, 5(4), 70-78.

Blankstein, K. R., Flett, G. L., Hewitt, P. L., \& Eng, A. (1993). Dimensions of perfectionism and irrational fears: An examination with the Fear Survey Schedule. Personality and Individual Differences, 15(3), 323-328. doi: 10.1016/0191-8869(93)90223-p

Boll, S., Bartholomaeus, M., Peter, U., Lupke, U., \& Gamer, M. (2016). Attentional mechanisms of social perception are biased in social phobia. Journal of Anxiety Disorders, 40, 83-93. doi: 10.1016/j .janxdis.2016.04.004 
Boucher, H., \& Ryan, C. A. (2011). Performance stress and the very young musician. Journal of Research in Music Education, 58(4), 329-345. doi: 10.1177/0022429410386965

Braden, A. M., Osborne, M. S., \& Wilson, S. J. (2015). Psychological intervention reduces self-reported performance anxiety in high school music students. Frontiers in Psychology, 6. doi: 10.3389/fpsyg .2015 .00195

Connor, K. M., Davidson, J. T. R., Churchill, L. E., Sherwood, A., \& Weisler, R. H. (2000). Psychometric properties of the Social Phobia Inventory (SPIN). The British Journal of Psychiatry, 176(4), 379-386. doi: 10.1192/bjp.176.4.379

Clark, D. M. (2001). A cognitive perspective on social phobia. In W. R. Crozier \& L. E. Alden (Eds.), International handbook of social anxiety (pp. 405-430). Chichester, UK: Wiley.

Crippa, J. A. S., de Lima Osório, F., Del-Ben, C. M., Filho, A. S., da Silva Freitas, M. C., \& Loureiro, S. R. (2008). Comparability between telephone and face-to-face structured clinical interview for DSM-IV in assessing social anxiety disorder. Perspectives in Psychiatric Care, 44(4), 241-247. doi: 10.1111/j.1744-6163.2008.00183.x

Damian, L. E., Negru-Subtirica, O., Stoeber, J., \& Băban, A. (2016). Perfectionistic concerns predict increases in adolescents' anxiety symptoms: A three-wave longitudinal study. Anxiety, Stress, $\mathcal{E}$ Coping, 30(5), 551-561. doi: 10.1080/10615806.2016.1271877

Damian, L. E., Stoeber, J., Negru, O., \& Băban, A. (2013). On the development of perfectionism in adolescence: Perceived parental expectations predict longitudinal increases in socially prescribed perfectionism. Personality and Individual Differences, 55(6), 688-693. doi: 10.1016/j.paid.2013.05.021

Fancourt, D., Aufegger, L., \& Williamon, A. (2015). Low-stress and high-stress singing have contrasting effects on glucocorticoid response. Frontiers in Psychology, 6(1242), doi: 10.3389/fpsyg.2015.01242

Fehm, L., \& Schmidt, K. (2006). Performance anxiety in gifted adolescent musicians. Journal of Anxiety Disorders, 20(1), 98-109. doi: 10.1016/j.janxdis.2004.11.011

Fishbein, M., Middlestadt, S. E., Ottati, V., Straus, S., \& Ellis, A. (1988). Medical problems among ICSOM musicians: Overview of a national survey. Medical Problems of Performing Artists, 3(1), 1-8.

Flett, G. L., Greene, A., \& Hewitt, P. L. (2004). Dimensions of perfectionism and anxiety sensitivity. Journal of Rational-Emotive $\mathcal{E}$ Cognitive-Behavior Therapy, 22(1), 39-57. doi: 10.1023/b:jore.0000011576 $.18538 .8 \mathrm{e}$

Flett, G. L., Hewitt, P. L., Blankstein, K., \& Gray, L. (1998). Psychological distress and the frequency of perfectionistic thinking. Journal of Personality and Social Psychology, 75(5), 1363-1381. doi: $10.1037 / / 0022-3514.75 .5 .1363$

Flett, G. L., Hewitt, P. L., Oliver, J. M., \& Macdonald, S. (2002). Perfectionism in children and their parents: A developmental analysis. In G. L. Flett \& P. L. Hewitt (Eds.), Perfectionism: Theory, research, and treatment (pp. 89-132). Washington, DC: American Psychological Association. doi: 10.1037/10458-004

Frost, R. O., Marten, P., Lahart, C., \& Rosenblate, R. (1990). The dimensions of perfectionism. Cognitive Therapy and Research, 14(5), 449-468. doi: 10.1007/bf01172967

Furmark, T., Tillfors, M., Everz, P.-O., Marteinsdottir, I., Gefvert, O., \& Fredrikson, M. (1999). Social phobia in the general population: prevalence and sociodemographic profile. Social Psychiatry and Psychiatric Epidemiology, 34(8), 416-424. doi: 10.1007/s001270050163

Ginsberg, D. L. ( 2004). Women and anxiety disorders: Implications for diagnosis and treatment. CNS Spectrums, 9(9), 1-3. doi: 10.1017/s1092852900001978

Goberman, A. M., Hughes, S., \& Haydock, T. (2011). Acoustic characteristics of public speaking anxiety and practice effects. Speech Communication, 53(6), 867-876. doi: 10.1016/j. specom.2011.02.005

Goodwin, R. D., Wall, M. M., Choo, T., Galea, S., Horowitz, J., Nomura, Y., ...Hasin, D. S. (2014). Changes in the prevalence of mood and anxiety disorders among male and female current smokers in the United States: 1990-2001. Annals of Epidemiology, 24(7), 493-497. doi: 10.1016/j.annepi dem.2014.01.014

Gorges, S., Alpers, G. W., \& Pauli, P. (2007). Musical performance anxiety as a form of social anxiety? International Symposium on Performance Science, 1, 67-72. Retrieved from http://www.performances cience.org/ISPS2007/Proceedings/Rows/12Gorges\%20etal.pdf 
Hewitt, P. L., Flett, G. L., Sherry, S. B., Habke, M., Parkin, M., Lam, R. W., ... Stein, M. B. (2003). The interpersonal expression of perfection: Perfectionistic self-presentation and psychological distress. Journal of Personality and Social Psychology, 84(6), 1303-1325. doi: 10.1037/0022-3514.84.6.1303

Hofmann, S. G., Gerlach, A. L., Wender, A., \& Roth, W. T. (1997). Speech disturbances and gaze behavior during public speaking in subtypes of social phobia. Journal of Anxiety Disorders, 11(6), 573-585. doi: 10.1016/s0887-6185(97)00040-6

Hook, J. N., \& Valentiner, D. P. (2006). Are specific and generalized social phobias qualitatively distinct? Clinical Psychology: Science and Practice, 9(4), 379-395. doi: 10.1093/clipsy.9.4.379

Johnston, L. D., O'Malley, P. M., Bachman, J. G., \& Schulenberg, J. E. (2009). Monitoring the future: National survey results on drug use, 1975-2005: Secondary school students. PsycEXTRA Dataset. doi: 10.1037/e567272009-001

Juster, H. R., Heimberg, R. G., Frost, R. O., Holt, C. S., Mattia, J. I., \& Faccenda, K. (1996). Social phobia and perfectionism. Personality and Individual Differences, 21(3), 403-410. doi: 10.1016/01918869(96)00075-x

Kawamura, K. Y., Hunt, S. L., Frost, R. O., \& DiBartolo, P. M. (2001). Perfectionism, anxiety, and depression: Are the relationships independent? Cognitive Therapy and Research, 25(3), 291-301. doi: 10.1023/a:1010736529013

Kenny, D. T. (2006). Music Performance Anxiety: Origins, phenomenology, assessment and treatment. Context: A Journal of Music Research, 31, 51-64.

Kenny, D. T. (2009a). Negative emotions in music making: Performance anxiety. In P. Juslin \& J. Sloboda (Eds.), Handbook of music and emotion: Theory, research, applications. Oxford, UK: Oxford University Press.

Kenny, D. T. (2009b). The factor structure of the revised Kenny Music Performance Anxiety Inventory. Paper presented at the International Symposium on Performance Science, Auckland, New Zealand.

Kenny, D. T. (2011). The psychology of music performance anxiety. Oxford, UK: Oxford University Press.

Kenny, D. T., \& Ackermann, B. (2015). Optimising physical and psychological health in performing musicians. In S. Hallam, I. Cross \& M. Thaut (Eds.), Oxford handbook of music psychology, (2nd ed., pp. 633-647). Oxford, UK: Oxford University Press.

Kenny, D. T., Davis, P., \& Oates, J. (2004). Music performance anxiety and occupational stress amongst opera chorus artists and their relationship with state and trait anxiety and perfectionism. Journal of Anxiety Disorders, 18(6), 757-777. doi: 10.1016/j.janxdis.2003.09.004

Kenny, D., Driscoll, T., \& Ackermann, B. (2014). Psychological well-being in professional orchestral musicians in Australia: A descriptive population study. Psychology of Music, 42(2), 210-232. doi: 10.1177/0305735612463950

Kenny, D., Driscoll, T., \& Ackermann, B. (2016). Is playing in the pit really the pits?: Pain, strength, music performance anxiety, and workplace satisfaction in professional musicians in stage, pit, and combined stage/pit orchestras. Medical Problems of Performing Artists, 31(1), 1-7. doi: 10.21091/ mppa.2016.1001

Kenny, D. T., \& Osborne, M. S. (2006). Music performance anxiety: New insights from young musicians. Advances in Cognitive Psychology, 2(2), 103-112. doi: 10.2478/v10053-008-0049-5

Kessler, R. C., Berglund, P., Demler, O., Jin, R., Merikangas, K. R., \& Walters, E. E. (2005). Lifetime prevalence and age-of-onset distributions of DSM-IV disorders in the National Comorbidity Survey Replication. Archives of General Psychiatry, 62(6), 593-602. doi: 10.1001/archpsyc.62.6.593

Kringlen, E., Torgersen, S., \& Cramer, V. (2001). A Norwegian psychiatric epidemiological study. American Journal of Psychiatry, 158(7), 1091-1098. doi: 10.1016/0924-9338(96)88727-x

Larrouy-Maestri, P., \& Morsomme, D. (2014). The effects of stress on singing voice accuracy. Journal of Voice, 28(1), 52-58. doi: 10.1016/j.jvoice.2013.07.008

Lederman, R. J. (1999). Medical treatment of performance anxiety. Medical Problems of Performing Artists, 14(3), 117-121.

Magee, W. J., Eaton, W. W., Wittchen, H.-U., McGonagle, K. A., \& Kessler, R. C. (1996). Agoraphobia, simple phobia, and social phobia in the National Comorbidity Survey. Archives of General Psychiatry, 53(2), 159-168. doi: 10.1001/archpsyc.1996.01830020077009 
Meaney, M. J., Liebowitz, M. L., \& David Leonardo, E. (2015). Neurobiology of Anxiety Disorders. Psychiatry, 320-340. doi: 10.1002/9781118753378.ch20

Miller, K. E., \& Quigley, B. M. (2011). Energy drink use and substance use among musicians. Journal of Caffeine Research, 1(1), 67-73. doi: 10.1089/jcr.2011.0003

Mor, S., Day, H. I., Flett, G. L., \& Hewitt, P. L. (1995). Perfectionism, control, and components of performance anxiety in professional artists. Cognitive Therapy and Research, 19(2), 207-225. doi: 10.1007 /bf02229695

Nicholson, D. R., Cody, M. W., \& Beck, J. G. (2015). Anxiety in musicians: On and off stage. Psychology of Music, 43(3), 438-449. doi: 10.1177/0305735614540018

Nusseck, M., Zander, M., \& Spahn, C. (2015). Music performance anxiety in young musicians. Medical Problems of Performing Artists, 30(1), 30-37.

Oddo-Sommerfeld, S., Hain, S., Louwen, F., \& Schermelleh-Engel, K. (2015). Longitudinal effects of dysfunctional perfectionism and avoidant personality style on postpartum mental disorders: Pathways through antepartum depression and anxiety. Journal of Affective Disorders, 191, 280-288. doi: 10.1016/j.jad.2015.11.040

Osborne, M. S., \& Franklin, J. (2002). Cognitive processes in music performance anxiety. Australian Journal of Psychology, 54(2), 86-93. doi: 10.1080/00049530210001706543

Osborne, M. S., Greene, D. J., \& Immel, D. T. (2014). Managing performance anxiety and improving mental skills in conservatoire students through performance psychology training: A pilot study. Psychology of Well Being, 4(18), 1-17. doi: 10.1186/s13612-014-0018-3

Osborne, M. S., \& Kenny, D. T. (2005). Development and validation of a music performance anxiety inventory for gifted adolescent musicians. Journal of Anxiety Disorders, 19(7), 725-751. doi: 10.1016/j .janxdis.2004.09.002

Osborne, M. S., Kenny, D. T., \& Cooksey, J. (2007). Impact of a cognitive-behavioural treatment program on music performance anxiety in secondary school music students: A pilot study. Musicae Scientiae, 11(2_Suppl.), 53-84. doi: 10.1177/10298649070110s204

Osborne, M. S., \& Kenny, D. T. (2008). The role of sensitising experiences in music performance anxiety in adolescent musicians. Psychology of Music, 36(4), 447-462. doi: 10.1177/0305735607086051

Park, D., Ramirez, G., \& Beilock, S. L. (2014). The role of expressive writing in math anxiety. Journal of Experimental Psychology: Applied, 20(2), 103-111. doi: 10.1037/xap0000013

Patston, T. (2010). Cognitive mediators of music performance anxiety (PhD dissertation). The University of Sydney, Sydney, Australia.

Patston, T. (2014). Teaching stage fright? - Implications for music educators. British Journal of Music Education, 31(1), 85-98. doi: 10.1017/s0265051713000144

Patston, T., \& Osborne, M. S. (2016). The developmental features of music performance anxiety and perfectionism in school age music students. Performance Enhancement and Health, 4(1), 42-49. doi: 10.1016/j.peh.2015.09.003

Powell, D. H. (2004). Treating individuals with debilitating performance anxiety: An introduction. Journal of Clinical Psychology, 60(8), 801-808. doi: 10.1002/jclp.20038

Ranta, K., Kaltiala-Heino, R., Koivisto, A. M., Tuomisto, M. T., Pelkonen, M., \& Marttunen, M. (2007). Age and gender differences in social anxiety symptoms during adolescence: The Social Phobia Inventory (SPIN) as a measure. Psychiatry Research, 153(3), 261-270. doi: 10.1016/j.psychres.2006.12.006

Ringeisen, T., \& Raufelder, D. (2015). The interplay of parental support, parental pressure and test anxiety: Differences in adolescents. Journal of Adolescence, 45, 67-79. doi: 10.1016/j.adolescence.2015.08.018

Robson, K. E., \& Kenny, D. (2017). Music performance anxiety in ensemble rehearsals and concerts: A comparison of music and non-music major undergraduate musicians. Psychology of Music, 46(6), 868-885. doi: 10.1177/0305735617693472

Salmon, P. G. (1990). A psychological perspective on musical performance anxiety: A review of the literature. Medical Problems of Performing Artists, 5(1), 2-11. 
Sinden, L. M. (1999). Music performance anxiety: Contributions of perfectionism, coping style, selfefficacy, and self-esteem. Dissertation Abstracts International Section A: Humanities and Social Sciences, 60(3-A), 0590.

Soenens, B., Luyckx, K., Vansteenkiste, M., Luyten, P., Duriez, B., \& Goossens, L. (2008). Maladaptive perfectionism as an intervening variable between psychological control and adolescent depressive symptoms: A three-wave longitudinal study. Journal of Family Psychology, 22(3), 465-474. doi: $10.1037 / 0893-3200.22 .3 .465$

Stoeber, J., \& Eismann, U. (2007). Perfectionism in young musicians: Relations with motivation, effort, achievement, and distress. Personality and Individual Differences, 43(8), 2182-2192. doi: 10.1016/j. paid.2007.06.036

Stoeber, J., Madigan, D. J., Damian, L. E., Esposito, R. M., \& Lombardo, C. (2016). Perfectionism and eating disorder symptoms in female university students: The central role of perfectionistic self-presentation. Eating and Weight Disorders, 1-8. doi: 10.1007/s40519-016-0297-1

Stoeber, J., \& Otto, K. (2006). Positive conceptions of perfectionism: Approaches, evidence, challenges. Personality and Social Psychology Review, 10(4), 295-319. doi: 10.1207/s15327957pspr1004_2

Studer, R., Gomez, P., Hildebrandt, H., Arial, M., \& Danuser, B. (2011): Stage fright: Its experience as a problem and coping with it. International Archives of Occupational and Environment Health, 84(7), 761-771. doi: 10.1007/s00420-010-0608-1

Turner, S. M., Johnson, M. R., Beidel, D. C., Heiser, N. A., \& Lydiard, R. B. (2003). The Social Thoughts and Beliefs Scale: A new inventory for assessing cognitions in social phobia. Psychological Assessment, 15(3), 384-391. doi: 10.1037/1040-3590.15.3.384

Walker, I. J., \& Nordin-Bates, S. M. (2010). Performance anxiety experiences of professional ballet dancers: The importance of control. Journal of Dance Medicine E Science, 14(4), 133-145.

Wilson, G. D. (2002). Psychology for performing artists (2nd ed.). London, UK: Whurr.

\section{Author biographies}

Bianka Dobos studies health education in Doctoral School at University of Szeged. She did her MA at University of Miskolc, then finished BA in psychology. She currently works as a piano teacher in a music school. Her research area is performance anxiety among musicians, with a special focus on social anxiety disorder and perfectionism.

Bettina Piko is a behavioral scientist and full professor at the Department of Behavioral Sciences, University of Szeged, Hungary. She is a specialist in health psychology and community health. Her current research interests include addictions, stress, coping and anxiety.

Dianna Kenny is Professor of Psychology and Professor of Music at The University of Sydney, Australia. She is an international expert on music performance anxiety. Her special focus is on the individualisation of treatment for music performance anxiety in the most performance anxious musicians applying attachment theory and psychodynamic psychotherapy. Her other research interests include musician physical and mental health and occupational stress in professional musicians. 